\title{
A REVIEW OF RESULTS FROM CLINICAL TRIALS BASED ON CO- VARIANTS OF THE R-CHOP REGIMEN IN UNTREATED PATIENTS WITH DIFFUSE LARGE B-CELL LYMPHOMA
}

\author{
Vanya S. Popova \\ Clinic of Hematology, \\ Dr. Georgi Stranski University \\ Hospital - Pleven
}

\author{
Corresponding Author: \\ Vanya S. Popova \\ Clinic of Haematology, \\ Dr. Georgi Stranski University Hospital - \\ Pleven \\ 8A, G. Kochev Blvd. \\ 5800, Pleven \\ Bulgaria \\ e-mail: slavcheva_v@yahoo.com
}

Received: November 05, 2021

Revision received: November 20, 2021

Accepted: November 25, 2021

\section{Summary}

Since 2000, new drugs for treating lymphoproliferative diseases have been introduced in haematology, and their initial indications have been gradually expanded. Some of the so-called "target molecules" have shown good efficacy when treating some malignant non-Hodgkin lymphomas. The possibility of achieving therapeutic disease control in some indolent non-Hodgkin lymphomas using drugs with a different mechanism of action from that of cytostatics has logically raised the question of a change in therapeutic management in other lymphoproliferative diseases. Since 2010, clinical trials have been initiated with untreated patients with aggressive non-Hodgkin's lymphoma - diffuse large B-cell lymphoma as the primary target. The key aim of most clinical trials has been to compare the efficacy of the so-called „gold standard“ - rituximab, cyclophosphamide, doxorubicin, oncovin, prednisolone (R- $\mathrm{CHOP}$ ) versus its derivatives. The review discusses the results of completed clinical trials published on the Internet. These trials covered covariants of the R- CHOP regimen used as first-line treatment of patients with diffuse large B-cell lymphoma. The review also includes drugs registered in Bulgaria for the last ten years but with a different clinical indication at present. The results of five clinical trials in which obinotuzumab, venetoclax, lenalidomide, bortezomib, and ibrutinib were used are presented.

Keywords: diffuse large B-cell lymphoma, covariants, first-line

\section{Background}

Diffuse large B-cell lymphoma (DLBCL) is one of the most common non-Hodgkin lymphomas, about $25-40 \%$ of all lymphomas $[1,2]$. The disease belongs to the group of mature B-cell lymphoproliferative neoplasias and predominantly affects people over 60 . Though rare, DLBCL can develop due to a primary indolent lymphoma transformation, such as follicular non-Hodgkin's lymphoma, chronic lymphocytic leukemia [3]. When diagnosed, the majority of patients are in advanced stages. The clinical course is heterogeneous and, according to most authors, is associated with different cellular origins and molecular characteristics. Extranodal involvement is described in $40 \%$ of patients, and bone marrow involvement can be 
found in $11-27 \%$ of cases [4]. To date, in the ,era of immunochemotherapy," achieving complete remissions is possible, but for about $30-40 \%$ of patients, there is a risk of disease progression or relapse.

Based on clinical, morphological, immunological, and genetic characteristics [5] in 2016, the World Health Organization proposed a revised classification of DLBCL, dividing it into subtypes. This update was related to the everexpanding technological opportunities in the field of cancer diagnostics. In the past, Hodgkin lymphomas were initially differentiated from nonHodgkin lymphomas using light microscopy. The dynamic development of immunology and its widespread use for diagnosing hematologic diseases has contributed to the precise differentiation of lymphoproliferative diseases into early or mature B-, T- or NK-cell neoplasias. Based on gene expression profiles, two major phenotypic subtypes of DLBCL are currently distinguished: GCB- DLBCL- originating from germinal center $\mathrm{B}$ - lymphocytes, and $\mathrm{ABC}$ DLBCL (non-GCB), whose cellular origins are associated with activated B- lymphocytes [6]. The ABC subtype is associated with worse outcomes when standard immunochemotherapy is used [7]. It has been suggested that molecular subgroups reflect either developmental stages of B cells in lymphoid structures or the activity of different biological cellular programs [8]. Cellular origin can be determined through two main approaches: by GEP of formalin-fixed and paraffin-embedded tumor tissue materials or by immunohistochemical (ICH) labeling of cell markers in a defined algorithm [9]. Mutations, which affect genes encoding the synthesis of proteins involved in B-cell receptor signaling and the NFKB pathway, such as CD79b, MYD88, or genes involved in cell cycle control such as CDKN2A, contribute to the molecular pathogenesis of the ABC subtype of DLBCL [10]. Translocation $\mathrm{t}(14 ; 18)$ (q32; q21)/ IGHBCL2 is a more common pathological genetic disorder described in the GCB subtype[11], whereas BCL2 gene amplification is more frequently observed in the ABC subtype [12]. The BCL2 oncogene, located on chromosome $18 \mathrm{q} 21$, encodes a protein whose function is to maintain cell viability by inhibiting apoptosis [13]. Another chromosomal aberration observed in the GCB-subtype is a rearrangement of BCL6. The BCL6 oncogene is one of the major regulators involved in B-cell development in the germinal center [14]. In combination with chromosomal damage affecting the MYC gene or in the BCL2 $(+) / \mathrm{MYC}(+)$ combination, two other subgroups are formed. These subgroups can be identified by fluorescent in situ hybridization (FISH); these are the so-called „Doublehit"“(DH) or „Triple-hit" BCL2(+)/BCL6(+)/ $\mathrm{MYC}(+)$ B-cell lymphomas. The BCL6(+)/ $\mathrm{MYC}(+)$ combination is the less common $\mathrm{DH}$ variant compared to BCL2(+)/MYC [15]. Some mechanisms other than gene translocation can lead to increased protein expression on the tumor cell surface [16]. Increased expression of MYC protein is found in $30-50 \%$ of DLBCL cases and is associated with concomitant BCL2 expression in about $20-35 \%$ of cases [17]. The so-called double-expressing lymphomas (DE), defined based on ICH testing, have not been delineated as a distinct biological subtype as they can occur in both GCB and ABC subtypes. However, they are more commonly found in the latter [18]. ICH algorithms for determining the cell origin are considered acceptable because GEP is currently not a standard approach in clinical practice [19]. The classical algorithm proposed by Hans and colleagues with a panel of antibodies against CD10, BCL6, and MUM-1/IRF4, and the one proposed by Choi and colleagues, correlate well with the corresponding GEP results and highlight survival differences between GCB and nonGCB subtype of DLBCL [20]. Unfortunately, in about $10-15 \%$ of cases, the ICH study results are not always reproducible [21].

The international prognostic index (IPI) was first published in 1993 [22] and was based on clinical parameters (age, lactate dehydrogenase values, number of extranodal areas affected, disease stage, ECOG). Both IPI and its variants (R-IPI, NCCN-IPI) are routinely used to predict overall survival in patients with DLBCL [23]. Reports from unselected clinical trials have reported 5-year progressionfree survival of $70-75 \%$ and $75-80 \%$ overall survival for DLBCL patients treated with standard immunochemotherapy R-CHOP [24]. Therapeutic options are significantly more limited for patients assessed as high-risk based on the IPI. For this group of patients, there are 
no established therapeutic standards other than the $\mathrm{R}-\mathrm{CHOP}$ regimen, and participation in clinical trials is an option. Since 2010, clinical trials based on the CHOP regimen have been initiated, and various drugs have been added to this regimen to improve its efficacy.

Monoclonal antibodies were among the first drugs (Rituximab in particular) added to the standard CHOP regimen used as firstline treatment for patients with DLBCL. Over the years, the technological feasibility of monoclonal antibodies has improved, and a second-generation monoclonal antibody obinutuzumab has been approved in the field of hematology. The latter is a glycoengineered type II anti-CD20 monoclonal antibody that possesses more significant antibody-dependent cellular cytotoxicity compared to Rituximab [25]. The drug was included in the positive list of monoclonal antibodies reimbursed by the National Health Insurance Fund for Bulgaria in 2018 for the treatment of chronic lymphocytic leukemia and, two years later, it was approved in combination with a chemotherapeutic for the treatment of follicular lymphoma. In July 2011, the randomized, multicenter phase III GOYA clinical trial was initiated. The trial was focused on untreated patients with a histologically confirmed diagnosis of DLBCL. After randomization, patients were divided into two groups (Figure 1), and the primary endpoint of the clinical trial was to determine the time to progression. The secondary endpoints of the trial were to establish the median time to overall survival (OS), overall response, and median time to event-free survival (EFS) [26]. According to data from the final analysis published by Laurie

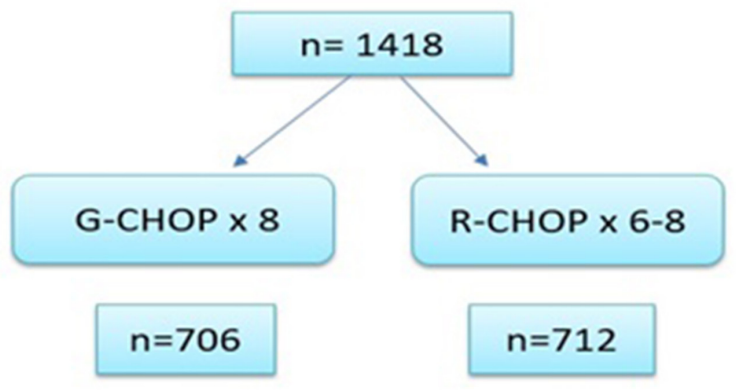

Figure 1. Patients distribution in GOYA clinical trial. The total number of patients included in the study was $n=1418$, of which 706 have received 8 courses Gazyvaro plus CHOP, and 712 have received 6-8 courses R-CHOP
H. Sehn et al., the G-CHOP combination was not superior to the classical R-CHOP treatment regimen (Table 1), and the incidence of late neutropenia was higher in the G-CHOP group $(8.7 \%)$ vs. the R-CHOP group (4.9\%) [27].

Inhibition of BCL2 represents an attractive therapeutic target in B-cell malignancies [28]. Venetoclax was the first oral BCL2- selective BH 3 - mimetic [29]. The drug has proven highly efficacious in the treatment of high-risk patients with B-cell chronic lymphocytic leukemia. The CAVALLI phase II non-randomized clinical trial studied the efficacy of Venetoclax used in a fixed dose of $800 \mathrm{mg} / \mathrm{d}$ added to a standard R-CHOP regimen. The cohort included untreated patients with various subtypes defined based on ICH and FISH [30]. Patients from the phase III GOYA study with characteristics similar to baseline were used as the control group. Venetoclax therapy was initiated on day 4 of cycle 1 , then on day 1 for cycles 2 to 8 to reduce and differentiate the potential risk of drug-induced tumor lysis syndrome (TLS). The analyses of clinical trial results showed prolonged 2-year PFS in highrisk Bcl-2 positive patients enrolled in the CAVALLI clinical trial, compared to patients in the GOYA trial (78\% vs. $62 \%$; HR, $0.55 ; 95 \%$ confidence interval, 0.34 - 0.89)[31]. Adding venetoclax to R-CHOP demonstrated increased yet controllable myelosuppression, with $86 \%$ of patients experiencing grade $3 / 4$ adverse haematolytic side events [30].

The ROBUST Phase III clinical trial is a randomized multicenter study designed to compare the efficacy of the immunomodulator lenalidomide administered at a fixed dose of $15 \mathrm{mg}$ from day 1 to day 14 , in combination with R-CHOP (R2-CHOP), versus placebo plus $\mathrm{R}-\mathrm{CHOP}$ in patients with untreated $\mathrm{ABC}$ - a subtype of DLBCL [32]. The results of the analysis performed on the parameters correlating with the efficacy of the therapeutic regimens such as ORR, CR, and OS showed no difference in the two groups of patients at a median followup of 27.1 months (Table 2). The safety profile of the R2-CHOP regimen did not differ from the recorded side effects when using the standard R-CHOP regimen [33].

A hallmark of the ABC subtype of DLBCL is the multiple genetic aberrations that lead to constitutive activation of the NF- $\mathrm{KB}$ signaling 
Table 1. Results from 5 clinical trials phase II or III comparing the efficacy of R-CHOP to its covariants in untreated patients with DLBCL. PFS- progression free survival, OS-overall survival

\begin{tabular}{|c|c|c|c|c|}
\hline Clinical study & $\begin{array}{c}\text { Number of } \\
\text { patients }\end{array}$ & PFS & os & Reference \\
\hline III GOYA & 1414 & $\begin{array}{c}\text { R- CHOP 62.6\% vs } \\
\text { G- CHOP 63.8\% } \\
\text { 5- year }\end{array}$ & $\begin{array}{c}\text { R-CHOP 77.7\% vs } \\
\text { G- CHOP 77. } 0 \% \\
\text { 5-year }\end{array}$ & Laurie H. Sehn ${ }^{27}$ \\
\hline $\begin{array}{l}\text { CAVALLI phase II/ } \\
\text { GOYA IPI 2-5 }\end{array}$ & $206 / 564$ & $\begin{array}{l}79.6 \text { vs } 67.3 \\
24-\text { months } \\
\end{array}$ & $\begin{array}{l}85.6 \text { vs } 80.9 \\
24-\text { months } \\
\end{array}$ & Morschhauser $\mathrm{F}^{42}$ \\
\hline ROBUST Phase III & 570 & $\begin{array}{c}\text { R2-CHOP 67\% } \\
\text { vs } \\
\text { R-CHOP 64\% } \\
\text { 2-year } \\
\end{array}$ & $\begin{array}{c}\text { R2-CHOP 79\% vs } \\
\text { R-CHOP } 80 \% \\
\text { 2- year }\end{array}$ & Nowakowski GS 33 \\
\hline$R E M o D L-B$ & 918 & $\begin{array}{c}\text { R-CHOP } 70.1 \% \\
\text { vs } \\
\text { RB- CHOP } 74.3 \% \\
\text { 30- months }\end{array}$ & $\begin{array}{c}\text { R-CHOP } 82.7 \% \text { vs } \\
\text { RB-CHOP } 83.6 \% \\
\text { 30- months }\end{array}$ & Davies A ${ }^{24}$ \\
\hline DBL3001 phase III & 838 & $\begin{array}{c}\text { R- CHOP } 68.1 \% \text { vs } \\
\text { IR-CHOP } 70.8 \% \\
\text { 36- months }\end{array}$ & $\begin{array}{c}\text { R-CHOP } 81.4 \% \text { vs } \\
\text { IR-CHOP } 82.8 \% \\
\text { 36- months }\end{array}$ & Younes $\mathrm{A}^{41}$ \\
\hline
\end{tabular}

Table 2. Comparison of two-year overall survival at median follow-up of 27.1 months, percentage of complete remissions and overall response, among 570 patients included in the clinical trial ROBUST. *ORR- Overall response rate, $* * \mathrm{CR}$ - complete response, $* * *$ overall survival

\begin{tabular}{ccc}
\hline Efficacy & R2-CHOP & R-CHOP \\
\hline${ }^{*}$ ORR, $\%$ & 91 & 91 \\
\hline$* *$ CR, $\%$ & 69 & 65 \\
\hline 2 -year $* * *$ OS $\%$ & 79 & 80 \\
\hline
\end{tabular}

pathway [34]. In 2001, a report by R. Eric Davis et al. proposed the idea of clinical trials combining chemotherapy with pharmacological inhibition of the NF-kB pathway [35]. Several years later, in 2011, the REMoDL-B clinical trial was initiated. The primary objective was to determine relapse-free survival using the bortezomib-R-CHOP combination in patients with untreated DLBCL. The drug is the first proteasome inhibitor [36] suggested to suppress $\mathrm{NF}-\kappa \mathrm{B}$ transcription factor activity [37]. The doses at which bortezomib was administered intravenously were $1.3 \mathrm{mg} / \mathrm{m} 2$, or $1.6 \mathrm{mg} / \mathrm{m} 2$ administered subcutaneously on days 1 and 8 for cycles 2- 6 in combination with standard $\mathrm{R}-\mathrm{CHOP}$ regimen doses. The cohort included a total of 928 patients, of whom 244 with ABCsubtype, 475 with GCB-subtype, and 199 NOS [38]. Patients were balanced into two groups depending on the cell-of-origin subtype (Figure
2). With a median follow-up of 29.7 months (95\% CI 29.0-32.0), the results of the analysis

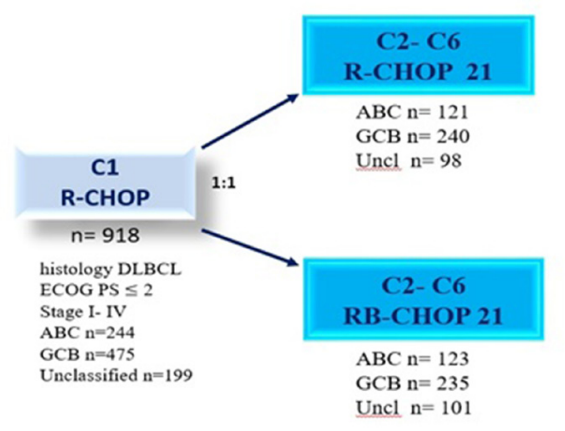

Figure 2. Patients who met the inclusion criteria for participation in the clinical trial ROBUST received one course of immunochemotherapy R- CHOP until the results of the molecular analysis were obtained, after which, based on cell-of- origin, the patients were balanced in two arms to receive either R-CHOP or RB-CHOP ( n- number of patients, uncl- unclassified, B- bortezomib) 
showed no difference in PFS when bortezomib was added to conventional R-CHOP in the two subgroups (GCB and ABC) [24]. No new serious adverse events were identified in the two groups of patients included in the clinical trial.

The B-cell receptor (BCR) involves a cascade sequence of activation of many kinase systems with a critical intermediate- activation of Bruton- tyrosine kinase and phosphoinositol - 3- kinases (PI3Ks)[39]. The activation of the Bruton- tyrosine kinase pathway plays a crucial role in several B-cell lymphoproliferative diseases [40]. Ibrutinib is the first oral Bruton's tyrosine kinase inhibitor currently approved in Bulgaria for treating B-chronic lymphocytic leukemia, mantle-cell lymphoma, and Waldenstrom macroglobulinemia. The DBL3001 Phase III clinical trial is a doubleblind study designed to determine the efficacy of the R-CHOP covariant with the addition of ibrutinib at a dose of $560 \mathrm{mg}$, administered once daily (21-day cycles) in untreated patients with the ABC subtype of DLBCL [41]. Patients were divided into two groups, with one half of the cohort treated with the regimen including Ibrutinib, Rituximab, Doxorubicin, Vincristine, Prednisolone (IR-CHOP ). The other half were treated with standard R-CHOP + placebo at a 21day repeat interval. With a median patient age of $62 \mathrm{yrs}$, the clinical trial results demonstrated an improvement in PFS and EFS in patients under 60 yrs treated with the IR-CHOP combination compared to standard R-CHOP one. In patients aged over 60 , the IR-CHOP treatment regimen was associated with increased toxicity, and IRCHOP did not improve EFS, PFS, and OS [41].

\section{Conclusion and Perspectives}

Advances in the study of the pathophysiological mechanisms of lymphoproliferative diseases have contributed to the introduction into clinical practice of a new generation of drugs, the socalled small molecules. These drugs target cellular components involved in processes associated with abnormal tumor growth. Integrating targeted therapy to the conventional chemotherapy regimen R-CHOP used as firstline treatment for DLBCL patients remains challenging. Future clinical trials based on standardized and generally accepted risk stratification methods and a change in therapeutic strategies, combining drugs targeting the tumor cell and its surrounding microenvironment would possibly contribute to improved survival of DLBCL patients.

\section{References}

1. Li S, Young KH, Medeiros LJ. Diffuse large B-cell lymphoma. Pathology. 2018 Jan;50(1):74-87.

2. Gascoyne DR. The biology of diffuse large b- cell lymphoma (DLBCL). Pathology. 2014;46(suppl 1):S32.

3. Pasqualucci L, Dalla-Favera R. Genetics of diffuse large B-cell lymphoma. Blood. 2018 May 24;131(21):2307-19.

4. Chiapella A, Vitolo U. Diffuse large b- cell lymphoma.In:Ghielmini M, Montoto S, editors. ESMO. Lymphomas Essential for Clinicians. Second edition Viganello-Lugano. 2015:31-7.

5. Mey U, Hitz F, Lohri A, Pederiva S, Taverna C, Tzankov A, et al. Diagnosis and treatment of diffuse large B-cell lymphoma. Swiss Med Wkly. 2012 January 30;142:w13511.

6. Nowakowski GS, Czuczman MS. ABC, GCB, and Double-Hit Diffuse Large B-Cell Lymphoma: Does Subtype Make a Difference in Therapy Selection? Am SocClinOncolEduc Book. 2015:e449-57.

7. Dunleavy K, Wilson WH. Appropriate management of molecular subtypes of diffuse large B-cell lymphoma. Oncology (Williston Park). 2014;28(4):326-34.

8. Quintanilla-Martinez L. The 2016 updated WHO classification of lymphoid neoplasias. HematolOncol. 2017 Jun;35Suppl 1:37-45.

9. Genova M, Balatzenko G. Cellular origin of diffuse large B-cell lymphoma. In: Predictive Biomarkers.

10. Bolen CR, Klanova M, Trneny M, Sehn LH, He $\mathrm{J}$, Tong $\mathrm{J}$, et al. Prognostic impact of somatic mutations in diffuse large B-cell lymphoma and relationship to cell-of-origin: data from the phase III GOYA study. Haematologica. 2020 Sep 1;105(9):2298-307.

11. Miao Y, Medeiros J, Li J, Young HK. Diffuse large B-cell lymphoma with molecular variations more than $\mathrm{ABC}$ and $\mathrm{GCB}$ classification. Precision Cancer Medicine. 2018:1-4.

12. Iqbal J, Neppalli VT, Wright G, Dave BJ, Horsman DE, Rosenwald A, Lynch J,et al. BCL2 expression is a prognostic marker for the activated B-cell-like type of diffuse large B-cell lymphoma. J ClinOncol. 2006 Feb 20;24(6):961-8. 
13. Riedell PA, Smith SM. Double hit and double expressors in lymphoma: Definition and treatment. Cancer (2018) 124: 4622-32.

14. Li S, Wang Z, Lin L, Wu Z, Yu Q, Gao F, Zhang J, Xu Y. BCL6 Rearrangement Indicates Poor Prognosis in Diffuse Large B-cell Lymphoma Patients: A Meta-analysis of Cohort Studies. J Cancer 2019;10(2):530-8.

15. Aukema SM, Siebert R, Schuuring E, van Imhoff GW, Kluin-Nelemans HC, Boerma EJ, Kluin PM. Double-hit B-cell lymphomas. Blood. 2011 Feb 24;117(8):2319-31.

16. Chiappella A, Crombie J, Guidetti A, Vitolo U, Armand P, Corradini P. Are We Ready to Treat Diffuse Large B-cell and High-Grade Lymphoma According to Major Genetic Subtypes? Hemasphere. 2019 July 31;3(5):e284.

17. Aggarwal A, Rafei H, Alakeel F, Finianos N A, Liu LM, El-Bahesh E et al. Outcome of Patients with Double-Expressor Lymphomas (DELs) Treated with R-CHOP or R-EPOCH. Blood 2016;128(22):5396.

18. Sehn LH, Salles G. Diffuse Large B-Cell Lymphoma. N Engl J Med. 2021 Mar 4;384(9):842-58.

19. Swerdlow H S, Campo E, Pileri A S, Harris L N, Stein H, Siebert R et al. The 2016 revision of the World Health Organization classification of lymphoid neoplasms. Blood 2016;127(20):2375-90.

20. Hans $\mathrm{P}$ Ch, Weisenburger D D, Greiner C T, Gascoyne D R, Delabie J, Ott G. et al. Confirmation of the molecular classification of diffuse large B-cell lymphoma by immunohistochemistry using a tissue microarray. Blood 2004;103(1):275-82.

21. Kumar V, Shrivastava MS, Meghal T, Chandra A B.Recent Advances in Diffuse Large B Cell Lymphoma. DOI: 10.5772/intechopen.74263.

22. Sehn H L, Berry B, Chhanabhai M, Fitzgerald C, Gill K, Hoskins $P$ et al.The revised International Prognostic Index (R-IPI) is a better predictor of outcome than the standard IPI for patients with diffuse large B-cell lymphoma treated with R-CHOP. Blood 2007;109(5):1857-61.

23. Zhong Q, Shi Y. Development and Validation of a Novel Risk Stratification Model for Cancer-Specific Survival in Diffuse Large B-Cell Lymphoma. Front Oncol. 2021 January 14; 10:582567.

24. Davies A, Cummin E T, Barrans R, Maishman T, Mamot C, Novak U et al. Gene-expression profiling of bortezomib added to standard chemoimmunotherapy for diffuse large B-cell lymphoma ( REMoDL-B):an open- lable, randomized, phase 3 trial. The Lancet oncology. 2019;(20):649-62.
25. Tobinai K, Klein C, Oya N, Fingerle-Rowson G. A Review of Obinutuzumab (GA101), a Novel Type II Anti-CD20 Monoclonal Antibody, for the Treatment of Patients with B-Cell Malignancies. Adv Ther. 2017;34(2):324-56.

26. Vitolo U, Trněný M, Belada D, Burke JM, Carella AM, Chua N, Abrisqueta P, Demeter J, Flinn I, Hong X, Kim WS, Pinto A, Shi YK, Tatsumi $\mathrm{Y}$, Oestergaard MZ, Wenger M, FingerleRowson G, Catalani O, Nielsen T, Martelli M, Sehn LH. Obinutuzumab or Rituximab Plus Cyclophosphamide, Doxorubicin, Vincristine, and Prednisone in Previously Untreated Diffuse Large B-Cell Lymphoma. J Clin Oncol. 2017 Nov 1;35(31):3529-37.

27. Sehn LH, Martelli $M$, Trněný $M$, Liu $W$, Bolen CR, Knapp A, Sahin D, Sellam G, Vitolo U. A randomized, open-label, Phase III study of obinutuzumab or rituximab plus CHOP in patients with previously untreated diffuse large B-Cell lymphoma: final analysis of GOYA. J Hematol Oncol. 2020 June 06;13(1):71.

28. Zelenetz D A, Salles G, Mason D K, Casulo C, Gouill L S, Sehn H L et al. Venetoclax plus Ror G-CHOP in non-Hodgkin lymphoma: results from the CAVALLI phase $1 \mathrm{~b}$ trial. Blood 2019; 133 (18): 1964-1976.

29. Roberts A, Huang D. Targeting BCL2 with BH3 Mimetics: Basic Science and ClinicalApplication of Venetoclax in Chronic Lymphocytic Leukemia and Related B Cell Malignancies. Clin. Pharmacol. Ther.2017;101:89-98.

30. Morschhauser M, Feugier P, Flinn W I, Gasiorowski E R, Greil R, Illés A et al. Venetoclax Plus Rituximab, Cyclophosphamide, Doxorubicin, Vincristine and Prednisolone (R-CHOP) Improves Outcomes in BCL2Positive First-Line Diffuse Large B-Cell Lymphoma (DLBCL): First Safety, Efficacy and Biomarker Analyses from the Phase II CAVALLI Study. Blood 2018;132 (Suppl 1):782.

31. Vitolo U, Novo M; Bcl-2 inhibition in DLBCL: "the times they are a-changing"? Blood 2021;137 (5):577-9.

32. Vitolo U, Witzig T, Gascoyne R, Scott D, Zhang Q, Jurczak W. et al., ROBUST: First report of phase III randomized study of lenalidomide/RCHOP (R2-CHOP) vs placebo/R-CHOP in previously untreated $\mathrm{ABC}$-type diffuse large B-cell lymphoma. Hematol Oncol. 2019;37:367.

33. Nowakowski GS, Chiappella A, Gascoyne RD, Scott DW, Zhang Q, Jurczak W, et al.ROBUST: A Phase III Study of Lenalidomide Plus R-CHOP Versus Placebo Plus R-CHOP in Previously Untreated Patients With ABC-Type Diffuse Large B-Cell Lymphoma. J Clin Oncol. 
2021 Apr 20;39(12):1317-28.

34. Pasqualucci L, Zhang B. Genetic drivers of NF-kB deregulation in diffuse large B-cell lymphoma. Semin Cancer Biol. 2016 Aug;39:26-31.

35. Davis E R, Brown D K, Siebenlist U, Staudt M L.Constitutive Nuclear Factor $\mathrm{kB}$ Activity Is Required for Survival of Activated B Cell-like Diffuse Large B Cell Lymphoma Cells . J Exp Med December 17 2001;194 (12):1861-74.

36. Chen D, Frezza M, Schmitt S, Kanwar J, Dou QP. Bortezomib as the first proteasome inhibitor anticancer drug: current status and future perspectives. Curr Cancer Drug Targets. 2011 Mar;11(3):239-53.

37. Accardi F, Toscani D, Bolzoni M, Palma D B, Aversa F, Giuliani N. Mechanism of Action of Bortezomib and the New Proteasome Inhibitors on Myeloma Cells and the Bone Microenvironment: Impact on MyelomaInduced Alterations of Bone Remodeling BioMed Research International, vol. 2015, Article ID 172458, 13 pages, 2015.

38. Davies A. Tailoring front-line therapy in diffuse large B-cell lymphoma: who should we treat differently?. Hematology Am Soc Hematol Educ Program 2017. 2017;1:284-94.

39. Goranov S, Goranova- MarinovaV. Chronic lymphocytic leukemia- new drugs replace the current standard. Hematology. 2019;1-2:13-21.

40. Castillo JJ, Treon SP, Davids MS. Inhibition of the Bruton Tyrosine Kinase Pathway in B-Cell Lymphoproliferative Disorders. Cancer J. 2016 Jan-Feb;22(1):34-9.
41. Younes A, Sehn LH, Johnson P, Zinzani PL, Hong X, Zhu J, Patti C, Belada D, Samoilova O, Suh C, Leppä S, Rai S, Turgut M, Jurczak W, Cheung MC, Gurion R, Yeh SP, LopezHernandez A, Dührsen U, Thieblemont C, Chiattone CS, Balasubramanian S, Carey J, Liu G, Shreeve SM, Sun S, Zhuang SH, Vermeulen J, Staudt LM, Wilson W; PHOENIX investigators. Randomized Phase III Trial of Ibrutinib and Rituximab Plus Cyclophosphamide, Doxorubicin, Vincristine, and Prednisone in Non-Germinal Center B-Cell Diffuse Large B-Cell Lymphoma. J Clin Oncol. 2019 May 20;37(15):1285-95.

42. Morschhauser F, Feugier P, Flinn IW, Gasiorowski R, Greil R, Illés Á, Johnson NA, Larouche JF, Lugtenburg PJ, Patti C, Salles GA, Trněný M, de Vos S, Mir F, Samineni D, Kim SY, Jiang Y, Punnoose E, Sinha A, Clark E, Spielewoy N, Humphrey K, Bazeos A, Zelenetz AD. A phase 2 study of venetoclax plus $\mathrm{R}-\mathrm{CHOP}$ as first-line treatment for patients with diffuse large B-cell lymphoma. Blood. 2021 Feb 4;137(5):600-9. 